\title{
Composition, richness and nestedness of gallery forest bird assemblages in an Amazonian savanna landscape: lessons for conservation
}

Joandro Pandilha ${ }^{1}$, José Júlio Toledo ${ }^{1}$, Luis Claudio Fernandes Barbosa ${ }^{2}$, William Douglas de Carvalho ${ }^{3}$, Jackson Cleiton de Sousa ${ }^{1}$, José Maria Cardoso da Silva ${ }^{\text {Corresp. } 4}$

\footnotetext{
1 Programa de Pós-Graduação em Biodiversidade Tropical, Universidade Federal do Amapá, Macapá, Amapá, Brazil

2 Conservation International - Brazil, Belém, Pará, Brazil

3 Programa de Pós-Graduação em Biodiversidade e Meio Ambiente, Universidade Federal da Grande Dourados, Dourados, Mato Grosso do Sul, Brazil

4 Department of Geography and Sustainable Development, University of Miami, Coral Gables, Florida, United States
}

Corresponding Author: José Maria Cardoso da Silva

Email address: jcsilva@miami.edu

Gallery forests are important to the maintenance of a substantial portion of the biodiversity in neotropical savanna regions, but management guidelines specific to this forest type are limited. Here, we use birds as study group to assess if: 1) functional traits can predict the abundance and occupancy of forest species within a savanna landscape, 2) habitat structures influence the taxonomic, functional, and phylogenetic diversity of forest assemblages, and 3) less diverse gallery forest assemblages are a nested subset of more diverse assemblages living near continuous forests. Then, we propose strategies on how gallery forests can be managed to maintain their species assemblages amidst the fast expansion of human activities across tropical savanna landscapes. We studied 26 sites of gallery forests in an Amazonian savanna landscape and found that: 1) habitat specificity is the only functional trait that predicts species abundance and occupancy across a landscape; 2) phylogenetic diversity is negatively correlated with understory foliage density; 3 ) the percentage of forests and savannas around sites is positively correlated with both phylogenetic and functional diversity; 5) increasing human activities around gallery forest negatively influences taxonomic and functional diversity; and 6) forest bird assemblages are not distributed at random across the landscape but show a nested pattern caused by selective colonization mediated by habitat filtering. Our combined findings have three implications for the design of conservation strategies for gallery forest bird assemblages. First, maintaining the connectivity between gallery forests and adjacent continuous forests is essential because gallery forest bird assemblages are derived from continuous forest species assemblages. Second, because most species use the savanna matrix to move across the landscape, effectively managing the savanna matrices where gallery forests are embedded is as important to maintaining viable populations of forest 
bird species as managing the gallery forest themselves. Third, in savanna landscapes planned to be used for agriculture production, protecting gallery forests alone is not enough. Instead, gallery forests should be protected with surrounding savanna buffers to avoid the detrimental effects (edge effects and isolation) of human activities on their biodiversity. 
3 Composition, richness and nestedness of gallery forest bird 4 assemblages in an Amazonian savanna landscape: lessons for 5 conservation

7 Joandro Pandilha ${ }^{1}$, José Júlio Toledo ${ }^{1}$, Luis Claudio Fernandes Barbosa ${ }^{2}$, William Douglas de

8 Carvalho $^{3}$, Jackson Cleiton de Sousa ${ }^{1} \&$ José Maria Cardoso da Silva ${ }^{4, *}$

${ }^{1}$ Universidade Federal do Amapá, Programa de Pós-Graduação em Biodiversidade Tropical,

12 Campus Universitário Marco Zero do Equador, Rodovia Juscelino Kubitschek, km 02, Bloco T, 13 Bairro Universidade, 68903-419, Macapá, AP, Brazil

$14{ }^{2}$ Conservação Internacional do Brasil, 14 de Abril 1186, Apt 205, 66060-460 Belém, Pará, 15 Brazil.

$16{ }^{3}$ Universidade Federal da Grande Dourados, Programa de Pós-Graduação em Biodiversidade e 17 Meio Ambiente, Rodovia Dourados/Itahum, Km12, 79804-970, Dourados, MS, Brazil.

$18{ }^{4}$ University of Miami, Department of Geography and Sustainable Development, 1300 Campo

19 Sano, Coral Gables, FL, 33124-4401

20

$21 *$ Corresponding author:

22 José Maria Cardoso da Silva

23 University of Miami, Department of Geography and Sustainable Development

241300 Campo Sano, Coral Gables, FL, 33124-4401

25 Email address: jcsilva@miami.edu 


\section{Abstract}

27 Gallery forests are important to the maintenance of a substantial portion of the biodiversity in

28 neotropical savanna regions, but management guidelines specific to this forest type are limited.

29 Here, we use birds as study group to assess if: 1) functional traits can predict the abundance and

30 occupancy of forest species within a savanna landscape, 2) habitat structures influence the

31 taxonomic, functional, and phylogenetic diversity of forest assemblages, and 3) less diverse

32 gallery forest assemblages are a nested subset of more diverse assemblages living near

33 continuous forests. Then, we propose strategies on how gallery forests can be managed to

34 maintain their species assemblages amidst the fast expansion of human activities across tropical

35 savanna landscapes. We studied 26 sites of gallery forests in an Amazonian savanna landscape

36 and found that: 1) habitat specificity is the only functional trait that predicts species abundance

37 and occupancy across a landscape; 2) phylogenetic diversity is negatively correlated with

38 understory foliage density; 3) the percentage of forests and savannas around sites is positively correlated with both phylogenetic and functional diversity; 5) increasing human activities around

40

41

42

43

44

45

46

47

48

49

50

51

52

53 gallery forest negatively influences taxonomic and functional diversity; and 6) forest bird assemblages are not distributed at random across the landscape but show a nested pattern caused by selective colonization mediated by habitat filtering. Our combined findings have three implications for the design of conservation strategies for gallery forest bird assemblages. First, maintaining the connectivity between gallery forests and adjacent continuous forests is essential because gallery forest bird assemblages are derived from continuous forest species assemblages. Second, because most species use the savanna matrix to move across the landscape, effectively managing the savanna matrices where gallery forests are embedded is as important to maintaining viable populations of forest bird species as managing the gallery forest themselves. Third, in savanna landscapes planned to be used for agriculture production, protecting gallery forests alone is not enough. Instead, gallery forests should be protected with surrounding savanna buffers to avoid the detrimental effects (edge effects and isolation) of human activities on their biodiversity. 


\section{Introduction}

55 Neotropical savannas regions are globally threatened due to commercial agricultural expansion

56 and silviculture (Silva \& Bates, 2002; Carvalho et al., 2019). These regions are home to

57 thousands of endemic species, many of which are at risk due to the lack of adequate protected

58 area systems (Klink \& Machado, 2005; Mustin et al., 2017; Carvalho \& Mustin, 2017).

59 Neotropical savanna regions are composed of landscapes where the matrix is dominated by open

60 and semi-open upland savannas, intersected by corridors of tall (up to $25 \mathrm{~m}$ ), evergreen gallery

61 forests that occur naturally as relatively narrow strips (usually no more than $500 \mathrm{~m}$ in width)

62 along watercourses (Silva, 1996; Kellman, Tackaberry \& Rigg, 1998; Veneklaas et al., 2005;

63 Pennington \& Ratter, 2006). These gallery forests, in turn, maintain most of the species of

64 savanna regions even though they occupy only a small portion of them (Redford \& Fonseca,

65 1986; Silva, 1995; Oliveira-Filho \& Ratter, 1995; Silva \& Santos, 2005).

66

67 Gallery forests are not isolated, as they form large dendritic networks following the rivers (Eiten,

68 1972; Oliveira-Filho \& Ratter, 1995; Silva, 1996). Usually, savanna rivers flow towards adjacent 69 areas covered by continuous forests. Thus, gallery forests have been considered conduits that 70 facilitate the colonization of savanna regions by species that have the center of their ranges in the 71 adjacent forest areas (Redford \& Fonseca, 1986; Oliveira-Filho \& Ratter, 1995; Silva, 1996).

72 However, biogeographic studies have shown that most forest species were not able to colonize 73 gallery forests, and the ones that did so do not extend their ranges deep into savannas (Oliveira74 Filho \& Ratter, 1995; Silva, 1996). This general pattern suggests that some attributes of gallery 75 forests can also constrain the expansion of forest species across savanna regions.

76

77 In general, the impact of a barrier on a species depends on the barrier permeability, which can be 78 79 defined as the degree by which a barrier constrains a species' range expansion. The barrier permeability, in turn, is a function of the interactions between barrier attributes and the characteristics (or functional traits) of the organism. Forman (1995) suggests that because forest corridors, such as gallery forests, are narrow, structurally distinct, and have large edge effects (a barrier attribute), they are not able to maintain viable populations of several forest interior species. Thus, their species assemblages are expected to be dominated by generalist species with good dispersal ability (two functional traits). This hypothesis has received support from studies 
85 on riparian forest corridors that were created due to human interventions on the landscapes (e.g., 86 Metzger, Bernacci \& Goldenberg, 1997; Lees \& Peres, 2008; Seaman \& Schulze, 2010; de 87 Oliveira Ramos \& dos Anjos, 2014; Lindsey, Bochio \& Anjos, 2019), but it has never been 88 formally tested in natural forest corridors, such as gallery forests. If Forman's hypothesis is 89 correct and the distributions of gallery forest species across savanna landscapes are indeed 90 determined by a combination of habitat attributes and inter-specific differences in habitat 91 specificity and dispersal ability, then local assemblages formed by such species are expected to 92 show a nested distribution pattern, in which less diverse assemblages are a nested subset of more 93 diverse assemblages living close to continuous forests (Ulrich, Almeida-Neto \& Gotelli, 2009;

94 Ulrich \& Almeida-Neto, 2012).

95

96 In this paper, we combine ecological field data, satellite image analysis, phylogenetic 97 information, and novel statistical techniques to respond to three main questions: 1) Can

98 functional traits predict the abundance and occupancy of forest bird species within savanna 99 landscapes? 2) Do habitat attributes influence the taxonomic, functional, and phylogenetic 100 diversity of forest bird assemblages across a savanna landscape? and 3) Are less diverse gallery 101 forest bird assemblages nested subsets of more diverse assemblages? We used birds as the study 102 group because they are diverse, well-known taxonomically, and sensitive to environmental 103 gradients (Sodhi et al., 2011; Sekercioglu, Wenny \& Whelan, 2016). Our ultimate aim was to 104 identify general ecological patterns and use these patterns to propose strategies on how gallery 105 forests can be managed to maintain their species assemblages amidst the fast expansion of 106 human activities across tropical savanna landscapes.

107

\section{Materials and methods}

109

\section{Study landscape}

111 We carried out our study in a 123,000 -ha savanna landscape $\left(0^{\circ} 12^{\prime} \mathrm{N}, 51^{\circ} 6^{\prime} \mathrm{W}\right)$ located between 112 the municipalities of Porto Grande and Macapá, Amapá, Brazil (Fig. 1). This savanna landscape 113 is within the Savannas of Amapá, the third largest block of Amazonian savanna (Carvalho \& 114 Mustin, 2017). Currently, this region is considered one of the last agricultural frontiers in Brazil, 
115 having been changed mainly due to the cultivation of soybeans, corn, and eucalyptus (Mustin et 116 al., 2017; Hilário et al., 2017). The climate is hot (average temperature of $27^{\circ} \mathrm{C}$ ) and humid 117 (average relative humidity of 81\%) (IEPA, 2008). Average annual precipitation from 1961 to 1181990 was $\sim 2700 \mathrm{~mm}$ with a well-marked dry season from August to November, when total 119 monthly rainfall is below $50 \mathrm{~mm}$ (Silva et al., 1997).

120 The study region has three main watersheds: Matapi, Curiaú, and Pedreira (Fig. 1). The rivers 121 and streams of the Matapi watershed connect the study region with the upland tropical forests on 122 Precambrian crystalline terrains located in the west. In contrast, the Curuá and Pedreira 123 watersheds' streams and rivers connect the study region with the seasonally flooded forests of the 124 Amazon Holocene floodplains located in the east (IEPA, 2008).

125 The landscape matrix is relatively well conserved. It is dominated by upland savannas and 126 flooded grasslands intersected by gallery forest corridors, with human impacts (mostly small127 scale agriculture areas and trails) limited to areas that were once occupied by upland savannas. In 128 general, upland savannas have a ground layer dominated by grass species of the genera 129 Rhynchospora, Axonopus, Paspalum, Polygala, Bulbostylis, and Miconia, and a woody layer (3$13010 \mathrm{~m}$ tall) that include large shrubs and trees such as Byrsonina crassifolia, Salvertia 131 convallariodora, Ouratea hexasperma, Curatella americana, Himatanthus articulatus,

132 Pallicourea rigida, and Hancornia speciosa (Sanaiotti, Bridgewater \& Ratter, 1997). Flooded 133 grasslands are at the bottom of some narrow valleys, where soils are shallow and permanently 134 inundated. These grasslands can sometimes include narrow stands of Mauritia and Mauritiella 135 palms (Silva et al., 1997). Gallery forests are narrow $(80-500 \mathrm{~m})$ and found only on either 136 cambisols or hydromorphic soils rich in organic matter along the wide valleys of rivers and 137 streams (Silva et al., 1997; Costa-Neto et al., 2017). They are evergreen with a well-defined 138 canopy composed of 20-30 m tall trees and a humid understory with many ferns, epiphytes, and 139 palms. The most common plant species were Mauritia flexuosa, Euterpe oleracea, Mauritiella 140 aculeata, Desmoncus sp., Annona paludosa, Coccoloba sp., Ficus sp., Symphonia globulifera, 141 Virola sp., Lecythis sp., and Hymenaea parvifolia (Costa-Neto et al., 2017).

\section{Site selection}

143 Our study sites were 26 gallery forests associated with low-order streams distributed across the 
144 study landscape (Fig. 1). We used two criteria to choose these sites. First, we placed 8-9 sites in

145 each of the three major watersheds in the study region to capture the regional environmental

146 heterogeneity (Fig. 1). Second, we selected the gallery forests that were at least $1.5 \mathrm{~km}$ apart

147 within each watershed to enhance spatial independence. In each site, we placed a $500 \mathrm{~m}$ long

148 transect to measure habitat structure and count birds, including their abundance and richness.

149 Perpendicularly to these forest transects, we set $400 \mathrm{~m}$ linear transects to measure how far

150 species recorded in the gallery forests moved into the savanna. Each transect was marked at $50 \mathrm{~m}$

151 intervals (henceforth, "distance classes") with colored ribbons nailed to tree trunks.

152

\section{Habitat attributes}

154 We quantified habitat attributes of gallery forests by taking measurements of both landscape and 155 vegetation structures. To analyze the landscape structure around each site, we first mapped the 156 landscape's land cover/use at a spatial resolution of $10 \mathrm{~m}$ using Sentinel-2 images (2015-2017) 157 and ArcGis 10.3. Using ArcGIS 10.3, we measured the gallery forest width at the transect 158 centroid as well as estimated the percentage of forests, savannas and anthropogenic ecosystems 159 within $500 \mathrm{~m}$ radius around the transect centroid. We used $500 \mathrm{~m}$ radius to avoid overlap with 160 the area of influence of other transects.

161 To measure vegetation structure, we set three plots measuring $75 \mathrm{~m} \times 2 \mathrm{~m}\left(150 \mathrm{~m}^{2}\right)$ located in the 162 beginning, middle, and end of each transect. In these plots, we took three measurements: (1) 163 canopy cover, (2) understory foliage density, and (4) tree height.

164 Canopy cover was measured using a leaf coverage index ranging from 0 to $100 \%$. This index is 165 estimated by analyzing the canopy photographs using the program "Gap Light Analysis Mobile 166 App" (GLAMA) (Tichý, 2016). We took four photographs at points located in each plot's corners, with the camera vertically positioned at the height of $1.6 \mathrm{~m}$ above ground. The average leaf coverage of the 12 photographs (four photographs $\times$ three plots) was used to measure the site's canopy cover.

170 Understory foliage density was measured as the number of foliage contacts between $0.5 \mathrm{~m}$ and 2 $171 \mathrm{~m}$ above ground with an aluminum pole $2 \mathrm{~m}$ tall and $5 \mathrm{~mm}$ in diameter. The pole was walked in 
172 front of the body in the middle of the plot ( $2 \mathrm{~m}$ wide), and all the touches of the three plots were

173 summed and used as a measure of the site's understory foliage density (Mantovani \& Martins, 174 1990).

175 Tree height was measured using a $4.5 \mathrm{~m}$ graduated ruler and a Bushnell Hypsometer (Scout 1000 176 Arc). The laser was focused on the highest branches or leaves, and the hypsometer data was 177 recorded. Then, the formula $\sin ($ Angle $\times \pi / 180) *$ Distance from the object +1.59 (eye height)

179 180

181

182 183 184 185 186 187 188 189 190 191 192 193 194 195 196

was used to obtain the height of each tree. We used the site's average tree height to characterize each site.

\section{Bird sampling}

In the forest transects, birds were counted using 10-min, unlimited radius point counts, one of the most commonly used methods for sampling birds in tropical regions (Bibby et al., 2000; Vielliard et al., 2010). With this method, the observer records all birds seen or heard within a pre-established period. Species flying above the canopy or flying through the sample area were not recorded. A total of 78 points (three points 200-m apart within each transect) was sampled, which was replicated four times. In the savanna transects, birds were counted using the fixed distance transect method, which consists of counting all birds detected visually or aurally within $50 \mathrm{~m}$ on each transect side (Bibby et al., 2000).

Because we counted birds twice during the rainy season (April and June 2018) and twice during the dry season (July and September 2018), we are confident that we covered all critical periods of the region's annual bird cycle. Birds were counted between 06:00 and 10:30, the peak period of bird activity, to maximize detection. The sequence by which transects were sampled was determined randomly one day before the sampling. J.P. surveyed all forest transects while J.C.S sampled all savanna transects. Both surveyors have extensive experience studying birds in the study region.

In each survey, the observer recorded the point location, the start and end time of the count, the recorded species' identity (observed or heard), and the number of individuals. In the savanna 
199 transects, forest's distance interval was also recorded. In the forest point count, the surveyor tried 200 to avoid double counting vocal species by noting their position in relation to the points. Species 201 flying over the transect were noted but not counted, and therefore were not included in the 202 analysis. Olympus Binoculars (7x32) were used in all counts. When necessary to identify a 203 species, vocalizations were recorded with a Zoom H1n recorder and directional microphone 204 Yoga-Ht81.

\section{Species functional traits}

206 We collected data for each species' five functional traits included in the analysis: body mass, 207 dispersal ability, diet, foraging stratum, and habitat specificity. These five traits were chosen 208 because previous studies have indicated that they are related to species abundance or range size 209 across different scales, from local to global (e.g., Pigot et al., 2018; Valente \& Betts, 2019; 210 Spake et al., 2020). Body mass for all species was gathered from the literature (Wilman et al. 211 2014). We used the Kipp's Index of wing morphology (KI) as a proxy for dispersal ability 212 because this information is available for all bird species in a standard format (Sheard et al., 213 2020). Based on field observations and literature (Wilman et al., 2014), we classified species into

214 four dietary groups (nectarivores, herbivores that eat mostly fruits and/or seeds, insectivores that 215 eat primarily insects and other invertebrates, and omnivores that combine herbivore and 216 insectivore diets) and five foraging strata (ground, understory, mid-level, canopy, and edges). As 217 an indicator of a species' habitat specificity, we used the weighted-average distance in which a 218 forest species was recorded in the different category distances from the forests along the savanna 219 transects.

220

\section{Species selection}

222 We gathered 3,770 records from 143 species in all our study sites (Table S1). However, we 223 restricted our analyses to 99 species (representing 2,411 records) associated with forest habitats 224 within savanna landscapes. Thus, we excluded all species considered as forest independent by 225 Silva (1995). Because the methods that we used do not provide a reliable estimate of abundance 226 and occupancy for all groups of birds (Bibby et al. 2000), we also excluded from our analyses all 227 species of Psittacidae (parrots and macaws), Ramphastidae (toucans and toucanets), obligate 
228 waterbirds, raptors, nocturnal species, and aerial insectivores.

229

\section{Species-level statistical analyses}

231 We estimated abundance and occupancy for each species. Species abundance was estimated at 232 site and at landscape level by dividing the number of points which the species was detected by 233 the total number of points sampled (Hutto et al. 1986). The occupancy of a species was estimated 234 by dividing the number of sites where the species was present by the total number of sampled 235 sites. We used Pearson's correlation test to assess the hypotheses that species abundance and 236 species occupancy are associated.

237 To evaluate if functional traits explain the abundance and occupancy of gallery forest bird 238 species within savanna landscapes, we used Phylogenetic Generalized Least Squares (PGLS) 239 models to avoid problems associated with the statistical nonindependence of related species 240 (Martins \& Hansen, 1997). Foraging stratum, a categorical variable, was added to the models 241 using a dummy coding (Mundry, 2014). Phylogenetic distances among species were estimated

242 based on an updated version (available in http://vertlife.org/phylosubsets) of the (Jetz et al., 243 2012) supertree based on the Hackett et al (2008) bone. Before proceeding with PGLS, we first 244 examined the variance inflation factors (VIF) to ensure that the predictor variables were 245 independent. All variables presented VIF $<3$ and were used in the model selection (Dormann et 246 al., 2013). Models were generated and ranked considering Akaike's information criterion 247 corrected for a small sample size (AICc, Burnham \& Anderson, 1998). Models with delta values $248\left(\Delta_{\mathrm{i}}\right)<2$, and high values of Akaike weights $\left(\mathrm{w}_{\mathrm{i}}\right)$ (i.e., closest to 1), were considered to be those 249 with the most robust support. We computed the best set of models, based on AICc (corrected 250 Akaike Information Criterion), using the "MuMIn" package (Barton, 2020) and the 251 model-averaging procedure. To average models, we computed mean values of estimates 252 assuming (full averages) and not assuming (conditional average) zero values for predictors in 253 models where they did not occur. PGLS model generation and selection were carried out in R 254 using the PGLS function in the package "caper" (Orme et al., 2018). We have followed the 255 recommendation of Revell (2010) and estimated the phylogenetic signal simultaneously using 256 Pagel's $\lambda$ (Pagel, 1999) with the regression model. 


\section{Assemblage-level statistical analysis}

258 We measured the three types of alpha diversity: taxonomic, functional, and phylogenetic. To 259 describe alpha diversities, we used the framework described by Chiu \& Chao (2014), which is 260 based on Hill numbers. Hill numbers are defined by parameter $q$, which considers the relative 261 abundance of species in determining the estimation of diversity, which facilitates the comparison 262 of data (Hill, 1973; Chiu \& Chao, 2014; Roswell, Dushoff \& Winfree, 2021). In our case, we 263 only used $q$ values that represent taxonomic, functional, and phylogenetic richness $(q=0)$, where 264 the abundance of species is ignored (Hill, 1973; Chiu \& Chao, 2014). All Hill numbers were 265 estimated with the R package "hillR" (Li, 2018). For functional richness, the Hill numbers 266 incorporate an array of functional distances constructed from the functional traits of the species

267 (see Chiu \& Chao, 2014). For phylogenetic richness, the Hill numbers incorporate a phylogenetic 268 tree (Li, 2018).

269

270 We used hierarchical partitioning (Chevan \& Sutherland, 1991; Cisneros et al. 2015) to identify

271 the habitat attributes that best accounted for variation in each of the three dimensions of

272 biodiversity. Statistical significance of the independent contribution of each explanatory variable

273 was determined using a randomization approach with 1000 iterations and an alfa-level of 0.05

274 (Mac Nally \& Walsh, 2020). Hierarchical partitioning and associated randomization tests were 275 executed using the R package 'hier.part' (MacNally \& Walsh, 2020).

276

277 To test the hypothesis that less diverse bird assemblages are a nested subset of more diverse 278 assemblages, we carried out taxonomic, phylogenetic, and functional nestedness analyses.

279 Presence-absence matrices were first constructed where species were in the columns and sites 280 were in the rows. Taxonomic nestedness was then estimated using the NODF index (Nestedness 281 Metric Based on Overlap and Decreasing Fill). We chose NODF because it has more robust 282 statistical properties than other indices and quantifies the degree to which each site is nested in 283 each of the other sites (Almeida-Neto et al., 2008). We evaluated the significance of the 284 taxonomic nestedness using the fixed-fixed null model (999 permutations) based on the 285 "quasiswap" algorithm (Miklós \& Podani, 2004). Both NODF estimation and the significance 286 test were conducted using the R package 'vegan' (Oksanen et al., 2019).

287 To estimate functional (traitNODF) and phylogenetic (phyloNODF) nestedness, we used an 
288 extension of the NODF index called treeNODF index (Melo, Cianciaruso \& Almeida-Neto, 289 2014), the same phylogeny used for the Phylogenetic Generalized Least Squares (PGLS) models, 290 and a functional dendrogram created by using five functional traits (body mass, wing 291 morphology, dispersal potential, diet, and foraging stratum). The functional dendrogram 292 represents species similarity for the five functional traits and was generated from the function 293 gawdis and UPGMA clustering algorithm. We used the gawdis function because there are 294 problems in combining quantitative and categorical traits into multi-trait dissimilarities using 295 Gower distance (Pavoine et al., 2009). Function gawdis balances the different traits when 296 computing multi-trait dissimilarities, finding weights that minimize the differences in the 297 correlation between the dissimilarity of each trait and the multi-trait (Bello et al., 2020). In 298 general, the treeNODF index assesses the proportion of functional/phylogenetic diversity present 299 in functionally/phylogenetically impoverished assemblages that are present in 300 functionally/phylogenetically rich assemblages (Melo, Cianciaruso \& Almeida-Neto, 2014). In 301 addition, we partitioned the traitNODF and phyloNODF into their two components: S.fraction 302 and topoNODF. The S.fraction represents the degree to which assemblages are or are not nested 303 due to having assemblages composed of the same or different species. In contrast, topoNODF 304 represents the degree to which assemblages are nested or not within the functional dendrogram 305 or phylogenetic tree (Melo, Cianciaruso \& Almeida-Neto, 2014). The treeNODF index was 306 estimated using the R package 'CommEcol' (Melo, 2019). The significance of the observed traitNODF and phyloNODF and their component values (S.fraction and topoNODE) were 308 determined using a permutation null model (999 permutations).

309

\section{Results}

311

\section{Species abundance and occupancy}

313 Species abundance and species occupancy are positively correlated (Pearson's correlation 314 coefficient, $\mathrm{r}=0.91, \mathrm{df}=97, \mathrm{p}<0.001$ ). Among the 99 species included in our analyses (Table 315 S1, Fig. S1), most of them have a low abundance index $($ range $=0.95-125.9$, median $=12.5)$ and 316 low occupancy index (range $=0.038-1$, median $=0.26$ ). Four species had the highest abundance 317 indices (Fig. S1). Three of them were recorded in all 26 sites: a hummingbird (Phaethornis 318 ruber), a small insectivore flycatcher (Lophotriccus galeatus), and an omnivorous thrush (Turdus 
319 leucomelas). However, the most abundant species (a small insectivore flycatcher, Tolmomyias

320 flaviventris) was recorded in 25 sites. Among the rarest species, 26 species were recorded in less

321 than two sites (Fig. S1). All of them had low abundance indices (range $=0.96-2.88$, median $=$

322 1.92). Most of the rare species are interior forest species, including, for instance, a large tinamou

323 (Tinamus major), six woodcreepers (Dendrexetastes rufigula, Dendrocolaptes certhia,

324 Dendrocolaptes picumnus, Lepidocolaptes albolineatus, Nasica longirostris and Xiphorhynchus

325 obsoletus) and two antbirds (Myrmoderus ferrugineus, Mymophylax atrothorax).

326

327 The best models (i.e., the ones with the lowest AICcs) predicting species abundance (Table S2)

328 and species occupancy (Table S3) from functional traits included four out of five functional traits

329 examined: habitat specificity, Kipp's Index, foraging stratum groups, and body mass. However,

330 habitat specificity is the only one of these traits that has a positive and significant correlation with

331 both abundance and occupancy (Table 1, Fig. 2).

332

\section{Species assemblages}

334 We detected different patterns of relationships between indicators of landscape and vegetation 335 structure with diversity estimates (Fig. 3; Table S4). The proportion of anthropogenic area 336 around the sites was negatively correlated with taxonomic, functional and phylogenetic diversity.

337 In contrast, forest and savanna areas are associated positively with functional and phylogenetic 338 diversity. Understory foliage density is negatively associated with phylogenetic diversity.

339

340 The nestedness analysis indicated that the less diverse assemblages are nested subsets of the most 341 diverse assemblages (Fig. 4). This pattern holds when analyzing taxonomic (NODF $=53.5, \mathrm{p}<$ 3420.01 ; Figure 4), phylogenetic (phyloNODF $=64.6, \mathrm{p}<0.01$ ) and functional (treeNODF $=67.1, \mathrm{p}$

$343<0.01)$ nestedness. In addition, we found that phylogenetic and functional nestedness is driven 344 mostly by changes in taxonomic species composition (S.fraction $=52.9$ and 54.6 , respectively) 345 rather than by functional or phylogenetic tree topology (topoNODF $=14.1$ and 10.1, 346 respectively).

348 Discussion

349 Species abundance and species occupancy of gallery forest birds are correlated at the landscape 
350 level. This result matches what has been reported in several studies at multiple spatial and 351 temporal scales (Gaston et al., 2000; Borregaard \& Rahbek, 2010; Webb, Freckleton \& Gaston, 352 2012). This general pattern is possibly an outcome of the interactions between resource-based 353 and population dynamic mechanisms (Gaston, 2003; Borregaard \& Rahbek, 2010). Resource-

354 based mechanisms are determined by habitat attributes, which set the spatial distribution and size 355 of potentially habitable areas of a species in a landscape. In contrast, population dynamic 356 mechanisms, such as population growth, habitat specificity, and dispersal ability, are determined 357 by species functional traits and set a proportion of the habitable sites that a species occupies at 358 any given time. Our results indicate that only habitat specificity can be considered as a robust 359 predictor of both species abundance and occupancy in gallery forests among all functional traits examined. Among gallery forest birds, those that move deeper into the savanna matrix for at least part of their annual life cycles are the ones most likely to maintain large local populations and occupy more gallery forests.

363

364 365 366

367 368 369 370 371 372 373 374 375 376 components of savanna bird assemblages (Boss \& Silva, 2015) and their presence within savanna 377 landscapes requires gallery forests (Silva et al. 1995). Gallery forest avifaunas inhabiting 378 Amazonian savannas are not novel assemblages formed by the influence of human activities in 379 the region (Young, 2014). In contrast, they are unique assemblages composed of species derived 380 from the different forest ecosystems that surround the landscapes dominated by savanna

In general, species assemblages living in gallery forests are dominated by generalist species that can use savannas to spread out across the landscape but not by species with high dispersal capacity. Therefore, our results only partially support Forman's hypothesis that most species living in these habitats should exhibit both traits (Forman, 1995). In addition, we found that gallery forests can also maintain populations of forest interior species although in low population density. For instance, if we consider all species foraging in the midstory, understory, and ground, more than half of the species we recorded in our sites can be classified as forest interior species.

71 Dominant species in gallery forests are either forest canopy or early-successional species that are 372 more tolerant to habitat changes and open spaces. Within the Amazon, they are found mostly in 73 seasonally flooded forests and second-growth forests (Novaes, 1973; Silva, Uhl \& Murray, 1996;

74 Borges, 2007) and are rare or absent in landscapes dominated by pristine continuous forests (Rutt 375 et al., 2019). Although versatile in their habitat preferences, these species are not core 
381 vegetation.

382

383 Indicators of landscape structure explained more the variation of the three biodiversity

384 dimensions that indicators of vegetation structure. Among the indicators of vegetation structure

385 only understory foliage density was negatively correlated with phylogenetic diversity, indicating

386 that foliage density can have negative effects on the abundance of some monophyletic groups of

387 birds that live in the forest interior and were represented in our sample. We found that increasing

388 human activities in the landscape is negatively correlated with taxonomic, functional and

389 phylogenetic diversity of gallery forests. Furthermore, our results show that the proportion of

390 savanna and forest around the sites is positively associated with functional and phylogenetic

391 diversity. This is a new finding and supports the notion that in tropical landscapes, extrinsic

392 factors, such as matrix dynamics, are at least as important as intrinsic factors to explain the

393 ecological processes operating within habitat patches (Gascon et al., 1999; Boesing, Nichols \&

394 Metzger, 2018; Stouffer, 2020). Because gallery forests are important to the maintenance of

395 freshwater resources relevant to human activities, human pressures on neotropical savanna

396 landscapes occur generally on the upland savannas adjacent to gallery forests, rather than in the

397 gallery forest themselves (Mustin et al., 2017). We suggest that land cover changes in the

398 savanna matrix negatively influence the taxonomic, functional and phylogenetic diversity of bird

399 assemblages of gallery forests by simultaneously increasing isolation and edge effects. In

400 tropical forests, both isolation and edge effects are known to reduce the diversity of neotropical

401 forest birds (Lees \& Peres, 2006, 2009; Banks-Leite, Ewers \& Metzger, 2010; Stouffer, 2020).

402 Isolation reduces species diversity by reducing the flow of individuals and species between

403 habitat patches and thus increasing the likelihood of random local extinction. Gallery forests

404 birds can move across the landscape either by following the gallery forest networks along the

405 rivers or by crossing the savanna matrix. If birds that cross the savanna matrix are not able to use

406 the anthropogenic vegetation that surround them, then they can become partially isolated and,

407 over time, decline (Tubelis, Cowling \& Donnelly, 2004; Tubelis, Lindenmayer \& Cowling,

408 2004). On the other hand, edge effects reduce species diversity by eliminating microhabitats used

409 by specialist forests species. Although edge effects are the norm in gallery forests because they

410 are naturally narrow habitats (de Oliveira Coelho et al., 2016), they tend to increase substantially 
411 if the adjacent upland savannas are removed and replaced by agriculture fields (Nóbrega et al., 412 2020).

413

414 As predicted, gallery forest bird species are not randomly distributed across tropical savanna 415 landscapes. Instead, less diverse bird assemblages are a nested subset of more diverse 416 assemblages generally located near the areas of continuous forests. This nestedness pattern holds 417 when considering all three dimensions (taxonomic, functional, and phylogenetic) of species 418 diversity. Moreover, we found that nestedness is driven mostly by changes in species 419 composition across sites. Several biological processes can explain nestedness in biological 420 assemblages, but the most likely alternatives are selective extinction and selective colonization 421 (Ulrich, Almeida-Neto \& Gotelli, 2009). Nestedness by selective extinction occurs when a 422 habitat is retracting in a region. As a consequence, species are locally extinct because they have 423 different susceptibilities to habitat fragmentation and reduction (Patterson, 1987, 1990). On the 424 other hand, selective colonization occurs when the habitat in a region is expanding from a place 425 with a species pool composed of species with different dispersal abilities (Darlington, 1957; 426 Kadmon, 1995; Dardanelli \& Bellis, 2020). Because gallery forests are expanding rather than 427 retracting over neotropical savannas under the current climate (Cole, 1986; Oliveira-Filho \& 428 Ratter, 1995), we suggest that selective colonization is the most likely process leading to 429 nestedness in gallery forest bird assemblages. However, our results show that selective 430 colonization can be mediated by habitat filtering, as forest species with low habitat specificity 431 can use forest expansion to colonize more gallery forests patches than species with high habitat 432 specificity. This inter-specific difference in habitat specificity results in a pattern in which due to 433 taxonomic turnover across sites, the most diverse gallery forests support species with both high 434 and low habitat specificity, whereas less diverse gallery forests support only the ones with low 435 habitat specificity.

436

437 Three main recommendations for the long-term management of gallery forests can be proposed 438 based on our results. First, maintaining the connectivity between gallery forests and adjacent 439 continuous forests is essential because gallery forest bird assemblages are derived from 440 continuous forest species assemblages through a process of selective colonization. Second, 441 because most species use the savanna matrix to move across the landscape, effectively 
442 managing the savanna matrices where gallery forests are embedded is as important to

443 maintaining viable populations of forest bird species as managing the gallery forest themselves.

444 Third, in savanna landscapes planned to be used for agriculture production, protecting gallery

445 forests alone is not enough. Instead, gallery forests should be protected with surrounding savanna

446 buffers to avoid the detrimental effects (edge effects and isolation) of human activities on their

447 biodiversity. Although several countries have specific legislation to safeguard the connectivity of

448 gallery forests due to their importance for water protection and flood regulation, they usually do

449 not consider the importance of managing the savanna matrix or the maintenance of savanna

450 buffers (Tubelis, Cowling \& Donnelly, 2004). In Brazil, for instance, there is a modern

451 conservation law that regulates the use of native ecosystems on private lands (Law $\mathrm{N}^{\circ}$.

452 12,651/12). This law considers gallery forests to be APPs (Áreas de Proteção Permanente or

453 Permanent Preservation Areas), which are areas set aside to forever preserve water resources,

454 stability (of the landscape, soil, and geology), biodiversity (facilitating the gene flow of fauna

455 and flora), and human well-being (Silva, Pinto \& Scarano, 2021). The law defines parameters

456 (e.g., river widths, slopes, and altitude) for landowners to demarcate these APPs, but the

457 management of the savanna matrix and the inclusion of savanna conservation buffers around

458 gallery forests are not included among these parameters.

459

460

\section{Conclusion}

462 Our results show that gallery forests are important biodiversity reservoirs in savanna landscapes

463 because they maintain populations of both forest dependent and semi-dependent species that are 464 not able to live in savannas (Silva, 1996; Silva et al., 1997; Piratelli \& Blake, 2006). In addition, 465 we found that: 1) habitat specificity is the only functional trait that predicts species abundance 466 and occupancy across a landscape; 2) phylogenetic diversity is negatively correlated with 467 understory foliage density; 3) the percentage of forests and savannas around sites is positively 468 correlated with both phylogenetic and functional diversity; 5) increasing human activities around 469 gallery forest negatively influences taxonomic and functional diversity; and 6) forest bird 470 assemblages are not distributed at random across the landscape but show a nested pattern caused 471 by selective colonization mediated by habitat filtering. Altogether, these findings provide a more 472 nuanced perspective on how forest birds are distributed in a tropical savanna landscape and 
473 guidance for the designing of sound conservation strategies for gallery forest bird assemblages.

474

\section{Acknowledgments}

476 We are grateful to Jackson Sousa and Rubenilson Pinto for assistance during fieldwork, Érica

477 Módena for feedback on the project, and Julie Topf for reviewing the drafts of the manuscript.

478 We thank the insightful comments by João Capurucho, Maria Alice Alves, and an anonymous

479 reviewer that helped to improve the manuscript significantly.

480

\section{References}

482 Almeida-Neto M, Guimarães P, Guimarães PR Jr, Loyola RD, Ulrich W. 2008. A consistent

483 metric for nestedness analysis in ecological systems: reconciling concept and measurement. Oikos 117:1227-1239. DOI: 10.1111/j.0030-1299.2008.16644.x.

Banks-Leite C, Ewers RM, Metzger J-P. 2010. Edge effects as the principal cause of area effects 486

487 on birds in fragmented secondary forest. Oikos 119:918-926. DOI: 10.1111/j.16000706.2009.18061.x.

489

490

491

492

493

494

495

496

497

Barton K. 2020. MuMIn': Multi-Model Inference. Available: https://cran.rproject.org/web/packages/MuMIn/MuMIn.pdf

Bello F, Botta-Dukát Z, Lepš J, Fibich P. 2020. Towards a more balanced combination of multiple traits when computing functional differences between species. Methods in ecology and evolution. DOI: 10.1111/2041-210x.13537.

Bibby CJ, Burgess ND, Hill DA, Hillis DM, Mustoe S. 2000. Bird Census Techniques. London: Academic Press.

Boesing AL, Nichols E, Metzger JP. 2018. Land use type, forest cover and forest edges modulate avian cross-habitat spillover. Journal of Applied Ecology 55:1252-1264. DOI: 10.1111/1365-2664.13032.

498

499

Borges SH. 2007. Bird Assemblages in Secondary Forests Developing after Slash-and-Burn Agriculture in the Brazilian Amazon. Journal of Tropical Ecology 23:469-477.

500 Borregaard MK, Rahbek C. 2010. Causality of the relationship between geographic distribution 501 and species abundance. The Quarterly review of biology 85:3-25. DOI: 10.1086/650265.

502 Boss RL, Silva JMC. 2015. Core and transient species in an Amazonian savanna bird 

assemblage. Revista Brasileira de Ornitologia 22:374-382.

504 505

506 507 508 509 510 511

512 513 514 515 516 517 518 519 520 521 522

523 524 525

526

527

528

529

530

531

532 533

Burnham KP, Anderson DR. 1998. Model Selection and Inference: A Practical InformationTheoretic Approach. Springer, New York, NY.

Carvalho WD, Mustin K. 2017. The highly threatened and little known Amazonian savannahs. Nature Ecology \& Evolution 1:100. DOI: 10.1038/s41559-017-0100.

Carvalho WD, Mustin K, Hilario RR, Vasconcelos IM, Eilers V, Fearnside PM. 2019. Deforestation control in the Brazilian Amazon: A conservation struggle being lost as agreements and regulations are subverted and bypassed. Perspectives in Ecology and Conservation 17:122-130. DOI: 10.1016/j.pecon.2019.06.002.

Chevan A, Sutherland M. Hierarchical partitioning. The American Statistician 45:90-66.

Chiu C-H, Chao A. 2014. Distance-based functional diversity measures and their decomposition: a framework based on Hill numbers. PloS one 9:e100014. DOI: 10.1371/journal.pone.0100014.

Cisneros LM, Fagan ME, Willig MR. 2015. Effects of human-modified landscapes on taxonomic, functional and phylogenetic dimensions of bat biodiversity. Diversity and Distributions 21:523-33.

Cole MM. 1986. The savannas:Biogeography and geobotany. London: Academic Press.

Costa-Neto SV, Miranda, Souza I, Rocha AES. 2017. Flora das savanas do estado do Amapá. In: Miranda-Junior JP, Bastos AM, Lima e Silva RB eds. Conhecimento e Manejo Sustentável da Biodiversidade Amapaense. São Paulo: Blucher, 61-90.

Dardanelli S, Bellis ML. 2020. Nestedness structure of bird assemblages in a fragmented forest in Central Argentina: the role of selective extinction and colonization processes. Animal biodiversity and conservation:17-29. DOI: 10.32800/abc.2021.44.0017.

Darlington PJ. 1957. Zoogeography. Nashville, TN: John Wiley \& Sons.

Dormann CF, Elith J, Bacher S, Buchmann C, Carl G, Carré G, Marquéz JRG, Gruber B, Lafourcade B, Leitão PJ, Münkemüller T, McClean C, Osborne PE, Reineking B, Schröder B, Skidmore AK, Zurell D, Lautenbach S. 2013. Collinearity: a review of methods to deal with it and a simulation study evaluating their performance. Ecography 36:27-46. DOI: 10.1111/j.1600-0587.2012.07348.x.

Eiten G. 1972. The cerrado vegetation of Brazil. The Botanical Review 38:201-341. DOI: $10.1007 / \mathrm{bf} 02859158$. 
534 Forman RTT. 1995. Land mosaics: the ecology of landscape and regions. Cambridge:

535 Cambridge University Press.

536 Gascon C, Lovejoy TE, Bierregaard RO Jr, Malcolm JR, Stouffer PC, Vasconcelos HL,

537 Laurance WF, Zimmerman B, Tocher M, Borges S. 1999. Matrix habitat and species

538 richness in tropical forest remnants. Biological conservation 91:223-229. DOI:

539 10.1016/S0006-3207(99)00080-4.

540 Gaston KJ. 2003. The structure and dynamics of geographic ranges. Oxford: Oxford University $541 \quad$ Press.

542 Gaston KJ, Blackburn TM, Jeremy J. D. Greenwood, Gregory RD, Quinn RM, Lawton JH. 2000. 543 Abundance-Occupancy Relationships. The Journal of applied ecology 37:39-59.

544 Hackett SJ, Kimball RT, Reddy S, Bowie RCK, Braun EL, Braun MJ, Chojnowski JL, Cox WA, 545

546

547

548

549

550

551

552

553

554

555

556

557 Han K-L, Harshman J, Huddleston CJ, Marks BD, Miglia KJ, Moore WS, Sheldon FH, Steadman DW, Witt CC, Yuri T. 2008. A phylogenomic study of birds reveals their evolutionary history. Science 320:1763-1768. DOI: 10.1126/science.1157704.

Hilário RR, de Toledo JJ, Mustin K, Castro IJ, Costa-Neto SV, Kauano ÉE, Eilers V, Vasconcelos IM, Mendes-Junior RN, Funi C, Fearnside PM, Silva JMC, Euler AMC, de Carvalho WD. 2017. The fate of an Amazonian savanna: Government land-use planning endangers sustainable development in Amapá, the most protected Brazilian state. Tropical Conservation Science 10:1940082917735416. DOI: 10.1177/1940082917735416.

Hill MO. 1973. Diversity and evenness: A unifying notation and its consequences. Ecology 54:427-432. DOI: $10.2307 / 1934352$.

Hutto RL, Pletschet SM, Hendricks P. 1986. A fixed-radius point count method for nonbreeding and breeding season use. The Auk 103:593-602. DOI: 10.1093/auk/103.3.593.

558 559

IEPA. 2008. Macrodiagnóstico do Estado do Amapá: Primeira aproximação do ZEE. Macapá,

560 Amapá, Brazil: IEPA.

561

Jetz W, Thomas GH, Joy JB, Hartmann K, Mooers AO. 2012. The global diversity of birds in space and time. Nature 491:444-448. DOI: 10.1038/nature11631.

562 Kadmon R. 1995. Nested species subsets and geographic isolation: A case study. Ecology $563 \quad 76: 458-465$. DOI: 10.2307/1941204.

564 Kellman M, Tackaberry R, Rigg L. 1998. Structure and function in two tropical gallery forest 
communities: implications for forest conservation in fragmented systems. The Journal of

566 applied ecology 35:195-206. DOI: 10.1046/j.1365-2664.1998.00300.x.

567

568

569

570

571

572

573

574

575

576

577

578

579

580

581

582

583

584

585

586

587

588

589

590

591

592

593

594

595

Klink CA, Machado RB. 2005. Conservation of the Brazilian Cerrado. Conservation biology 19:707-713. DOI: 10.1111/j.1523-1739.2005.00702.x.

Lees AC, Peres CA. 2006. Rapid avifaunal collapse along the Amazonian deforestation frontier. Biological conservation 133:198-211. DOI: 10.1016/j.biocon.2006.06.005.

Lees AC, Peres CA. 2008. Conservation value of remnant riparian forest corridors of varying quality for amazonian birds and mammals. Conservation Biology 22:439-449. DOI: 10.1111/j.1523-1739.2007.00870.x.

Lees AC, Peres CA. 2009. Gap-crossing movements predict species occupancy in Amazonian forest fragments. Oikos 118:280-290. DOI: 10.1111/j.1600-0706.2008.16842.x.

Li D. 2018. hillR: taxonomic, functional, and phylogenetic diversity and similarity through Hill Numbers. Journal of open source software 3:1041. DOI: 10.21105/joss.01041.

Lindsey BRA, Bochio GM, Anjos L dos. 2019. Bird species that occupy river edge in continuous forest tend to be less sensitive to forest fragmentation. Revista brasileira de ornitologia 27:172-186. DOI: $10.1007 / \mathrm{bf03544468.}$

Mantovani W, Martins FR. 1990. O método de pontos. Acta botanica Brasilica 4:95-122. DOI: $10.1590 / \mathrm{s} 0102-33061990000300011$.

Martins EP, Hansen TF. 1997. Phylogenies and the Comparative Method: A General Approach to Incorporating Phylogenetic Information into the Analysis of Interspecific Data. The American naturalist 149:646-667. DOI: 10.1086/286013.

MacNaly, R.M., Walsh, C. 2020. 'hier.part': Hierarchical Partitioning. https://cran.rproject.org/web/packages/hier.part/hier.part.pdf

Melo AS. 2019. CommEcol: Community Ecology Analyses. Available at: https://cran.rproject.org/web/packages/CommEcol/index.html.

Melo AS, Cianciaruso MV, Almeida-Neto M. 2014. treeNODF: nestedness to phylogenetic, functional and other tree-based diversity metrics. Methods in ecology and evolution 5:563-572. DOI: 10.1111/2041-210x.12185.

Metzger JP, Bernacci LC, Goldenberg R. 1997. Pattern of tree species diversity in riparian forest fragments of different widths (SE Brazil). Plant Ecology 133:135-152. DOI: 10.1023/A:1009791831294. 
596 Miklós I, Podani J. 2004. Randomization of presence-absence matrices: Comments and new 597 algorithms. Ecology 85:86-92. DOI: 10.1890/03-0101.

598 Mundry R. 2004. Statistical issues and assaumptions of phylogenetic generalized least squares.

599 In: Garamszegi L ed. Modern phylogenetic comparative methids and their appliucation 600 in evolutionary biology. Berlin: Springer, 131-153.

601

Mustin K, Carvalho WD, Hilario RR, Costa-Neto SV, Silva CR, Vasconcelos IM, Castro IJ, 602

603

604

605 Eilers V, Kauano EE, Mendes-Junior RNG, Funi C, Fearnside PM, Silva JMC, Euler AMC, Toledo JJ. 2017. Biodiversity, threats and conservation challenges in the Cerrado 606 607 608 609 of Amapa, an Amazonian savanna. Nature Conservation:107-127. DOI: 10.3897/natureconservation.22.13823.

Nóbrega RLB, Ziembowicz T, Torres GN, Guzha AC, Amorim RSS, Cardoso D, Johnson MS, Santos TG, Couto E, Gerold G. 2020. Ecosystem services of a functionally diverse riparian zone in the Amazon-Cerrado agricultural frontier. Global ecology and conservation 21:e00819. DOI: 10.1016/j.gecco.2019.e00819.

610

611

Novaes FC. 1973. Aves de uma vegetação secundária na foz do Amazonas. Belém: Museu

612

613

614 Paraense Emilio Goeldi.

615 de Oliveira Coelho GA, de Castro Nunes Santos Terra M, de Souza Almeida H, van den Berg E. 616 2016. What can natural edges of gallery forests teach us about woody community 617

618

619

620

621

622

623

624

625

626 RB, Simpson FL, Solymos P, H SMH, Szoecs E, Wagner H. 2019. Vegan: Community Ecology Package. performance in sharp ecotones? Journal of plant ecology 10:rtw083. DOI: 10.1093/jpe/rtw083.

de Oliveira Ramos CC, dos Anjos L. 2014. The width and biotic integrity of riparian forests affect richness, abundance, and composition of bird communities. Natureza \& Conservacao 12:59-64. DOI: 10.4322/natcon.2014.011.

Oliveira-Filho AT, Ratter JA. 1995. A study of the origin of central Brazilian forests by the analysis of plant species distribution patterns. Edinburgh Journal of Botany 52:141-194. DOI: $10.1017 /$ S0960428600000949.

Orme D, Freckleton R, Thomas G, Petxoldt T, Fritz S, Isaac N, Pearse W. 2018. 'caper': Comparative Analyses of Phylogenetics and Evolution in R. Available at: https://cran.r- 
627 project.org/web/packages/caper/caper.pdf.

628 Pagel M. 1999. Inferring the historical patterns of biological evolution. Nature 401:877-884.

629 DOI: $10.1038 / 44766$.

630 Patterson BD. 1987. The principle of nested subsets and its implications for biological

631 conservation. Conservation Biology 1:323-334. DOI: 10.1111/j.1523-

632 1739.1987.tb00052.x.

633 Patterson BD. 1990. On the Temporal Development of Nested Subset Patterns of Species

634 Composition. Oikos 59:330-342. DOI: 10.2307/3545143.

635 Pavoine S, Vallet J, Dufour A-B, Gachet S, Daniel H. 2009. On the challenge of treating various

636 types of variables: application for improving the measurement of functional diversity.

637 Oikos 118:391-402. DOI: 10.1111/j.1600-0706.2008.16668.x.

638 Pennington RT, Ratter JA. 2006. Neotropical Savannas and Seasonally Dry Forests: Plant

639 Diversity, Biogeography, and Conservation. Taylor \& Francis. DOI:

$640 \quad$ 10.1201/9781420004496.ch17.

641 Pigot AL, Jetz W, Sheard C, Tobias JA. 2018. The macroecological dynamics of species

642

643 coexistence in birds. Nature ecology \& evolution 2:1112-1119. DOI: 10.1038/s41559-

644 Piratelli A, Blake JG. 2006. Bird communities of the southeastern Cerrado region, Brazil. $645 \quad$ Ornitologia Neotropical 17:213-225.

646 Redford KH, Fonseca GAB. 1986. The role of gallery forests in the zoogeography of the 647 cerrado's non-volant mammalian fauna. Biotropica 18:126-135. DOI: 10.2307/2388755.

648 Revell LJ. 2010. Phylogenetic signal and linear regression on species data. Methods in ecology 649 and evolution 1:319-329. DOI: 10.1111/j.2041-210x.2010.00044.x.

650 Roswell M, Dushoff J, Winfree R. 2021. A conceptual guide to measuring species diversity. 651 Oikos 130:321-338. DOI: 10.1111/oik.07202.

652 Rutt CL, Jirinec V, Cohn-Haft M, Laurance WF, Stouffer PC. 2019. Avian ecological succession 653 in the Amazon: A long-term case study following experimental deforestation. Ecology and evolution 9:13850-13861. DOI: 10.1002/ece3.5822.

Sanaiotti T, Bridgewater S, Ratter J. 1997. A floristic study of the savanas vegetation of the state 656 of Amapá, Brazil, and suggestions for its conservation. Boletim do Museu Paraense Emilio Goeldi 13:3-29. 
658 Seaman BS, Schulze CH. 2010. The importance of gallery forests in the tropical lowlands of 659 Costa Rica for understorey forest birds. Biological conservation 143:391-398. DOI: $660 \quad$ 10.1016/j.biocon.2009.11.002.

661 Sekercioglu ÇH, Wenny DG, Whelan CJ (eds.). 2016. Why birds matter: Avian ecological 662 function and ecosystem services. University of Chicago Press.

663 Sheard C, Neate-Clegg MHC, Alioravainen N, Jones SEI, Vincent C, MacGregor HEA, 664 Bregman TP, Claramunt S, Tobias JA. 2020. Ecological drivers of global gradients in 665 666 avian dispersal inferred from wing morphology. Nature Communications 11:2463. DOI: 10.1038/s41467-020-16313-6.

668

Silva JMC. 1995. Birds of the cerrado region, South America. Steenstrupia 21:69-92.

669

Silva JMC. 1996. Distribution of Amazonian and Atlantic birds in gallery forests of the Cerrado

670 region, South America. Ornitologia neotropical 7:1-18.

671

672

673

674

675

676

677

678

679

680

681

682

683

684

685

686

687

Silva JMC, Bates JM. 2002. Biogeographic patterns and conservation in the South American Cerrado: A tropical savanna hotspot. Bioscience 52:225. DOI: 10.1641/00063568(2002)052[0225:BPACIT]2.0.CO;2.

Silva JMC, Oren DC, Roma JC, Henriques LMP. 1997. Composition and distribution patterns of the avifauna of an Amazonian upland savanna, Amapá, Brazil. Ornithological Monographs 48:743-762. DOI: 10.2307/40157565.

Silva JMC, Pinto LP, Scarano FR. 2021. Toward integrating private conservation lands into national protected area systems: Lessons from a megadiversity country. Conservation Science and Practice. DOI: 10.1111/csp2.433.

Silva JMC, Santos MPD. 2005. A importância relativa dos processos biogeográficos na formação da avifauna do Cerrado e de outros biomas brasileiros. In: Scariot AO, SouzaSilva, JC, Felfilli JM eds. Cerrado: ecologia, biodiversidade e conservação. Brasília, Brasil, 220-233.

Silva JMC, Uhl C, Murray G. 1996. Plant succession, landscape management, and the ecology of frugivorous birds in abandoned Amazonian pastures. Conservation Biology 10:491-503. DOI: 10.1046/j.1523-1739.1996.10020491.x.

Sodhi NS, Sekercioglu CH, Barlow J, Robinson SK. 2011. Conservation of Tropical Birds. Wiley-Blackwell.

688 Spake R, Soga M, Kawamura K, Cooke RS, Yamaura Y, Eigenbrod F. 2020. Regional 
689

690

691

692

693

694

695

696

697

698

699

700

701

702

703

704

705

706

707

708

709

710

711

712

713

714

715

716

717

718

719

variability in landscape effects on forest bird communities. Landscape ecology 35:10551071. DOI: 10.1007/s10980-020-01005-9.

Stouffer PC. 2020. Birds in fragmented Amazonian rainforest: Lessons from 40 years at the Biological Dynamics of Forest Fragments Project. The Condor. DOI: 10.1093/condor/duaa005.

Tichý L. 2016. Field test of canopy cover estimation by hemispherical photographs taken with a smartphone. Journal of vegetation science 27:427-435. DOI: 10.1111/jvs.12350.

Tubelis DP, Cowling A, Donnelly C. 2004. Landscape supplementation in adjacent savannas and its implications for the design of corridors for forest birds in the central Cerrado, Brazil. Biological Conservation 118:353-364. DOI: 10.1016/j.biocon.2003.09.014.

Tubelis DP, Lindenmayer DB, Cowling A. 2004. Novel patch-matrix interactions: patch width influences matrix use by birds. Oikos 107:634-644. DOI: 10.1111/j.00301299.2004.13420.x.

Ulrich W, Almeida-Neto M. 2012. On the meanings of nestedness: back to the basics. Ecography 35:865-871. DOI: $10.1111 / j .1600-0587.2012 .07671 . x$.

Ulrich W, Almeida-Neto M, Gotelli NJ. 2009. A consumer's guide to nestedness analysis. Oikos 118:3-17. DOI: 10.1111/j.1600-0706.2008.17053.x.

Valente JJ, Betts MG. 2019. Response to fragmentation by avian communities is mediated by species traits. Diversity and Distributions 25:48-60. DOI: 10.1111/ddi.12837.

Veneklaas EJ, Fajardo A, Obregon S, Lozano J. 2005. Gallery forest types and their environmental correlates in a Colombian savanna landscape. Ecography 28:236-252. DOI: 10.1111/j.0906-7590.2005.03934.x.

Vielliard JME, Almeida ME de C, Anjos L, Silva WR. 2010. Levantamento quantitativo por pontos de escuta e o Índice Pontual de Abundância (IPA). In: Matter SV, Straube FC, Accordi I eds. Ornitologia e Conservação: Ciência Aplicada, Técnicas de Pesquisa e Levantamento. Rio de Janeiro: Technical Books, 47-60.

Young KR. 2014. Biogeography of the Anthropocene: Novel species assemblages. Progress in Physical Geography 38:664-673. DOI: 10.1177/0309133314540930.

Webb TJ, Freckleton RP, Gaston KJ. 2012. Characterizing abundance-occupancy relationships: there is no artefact. Global ecology and biogeography 21:952-957. DOI: 10.1111/j.14668238.2011.00736.x. 
720 Wilman H, Belmaker J, Simpson J, de la Rosa C, Rivadeneira MM, Jetz W. 2014. EltonTraits

721 1.0: Species-level foraging attributes of the world's birds and mammals. Ecology

722 95:2027-2027. DOI: 10.1890/13-1917.1. 


\section{Table $\mathbf{1}$ (on next page)}

Model-averaged parameter estimates (standard deviation in parentheses) of phylogenetic generalized least squares models relating species traits, abundance and occupancy of 99 gallery forest birds in an Amazonian savanna landscape, Amapá, Brazil. 
1

2

3

\begin{tabular}{|c|c|c|c|c|c|c|}
\hline & \multicolumn{3}{|c|}{ Mean landscape abundance } & \multicolumn{3}{|c|}{ Occupancy } \\
\hline & Estimate & $z$ value & $p$ value & Estimate & $z$ value & $p$ value \\
\hline (Intercept) & 4.673 & 0.624 & 0.532 & 23.307 & 0.941 & 0.346 \\
\hline Habitat specificity & 0.065 & 2.321 & 0.020 & 0.263 & 3.475 & $<0.001$ \\
\hline Foraging stratum - Ground & -2.899 & 0.621 & 0.534 & -16.362 & 0.924 & 0.355 \\
\hline Foraging stratum - Mid-level & -0.160 & 0.061 & 0.951 & -3.696 & 0.380 & 0.703 \\
\hline Foraging stratum - Canopy and Edge & -3.047 & 0.866 & 0.386 & -4.583 & 0.467 & 0.640 \\
\hline Body mass & 1.028 & 0.447 & 0.654 & 5.099 & 0.602 & 0.546 \\
\hline Dispersal ability & 0.034 & 0.339 & 0.734 & 0.082 & 0.283 & 0.777 \\
\hline
\end{tabular}


Figure 1

Distribution of the study sites across an Amazonian savanna landscape in Amapá, Brazil. The distribution of the sites by watersheds is as follows: Curiaú (sites 1 to 9), Pedreiras (sites 10 to 18), and Matapi (sites 19 to 16).

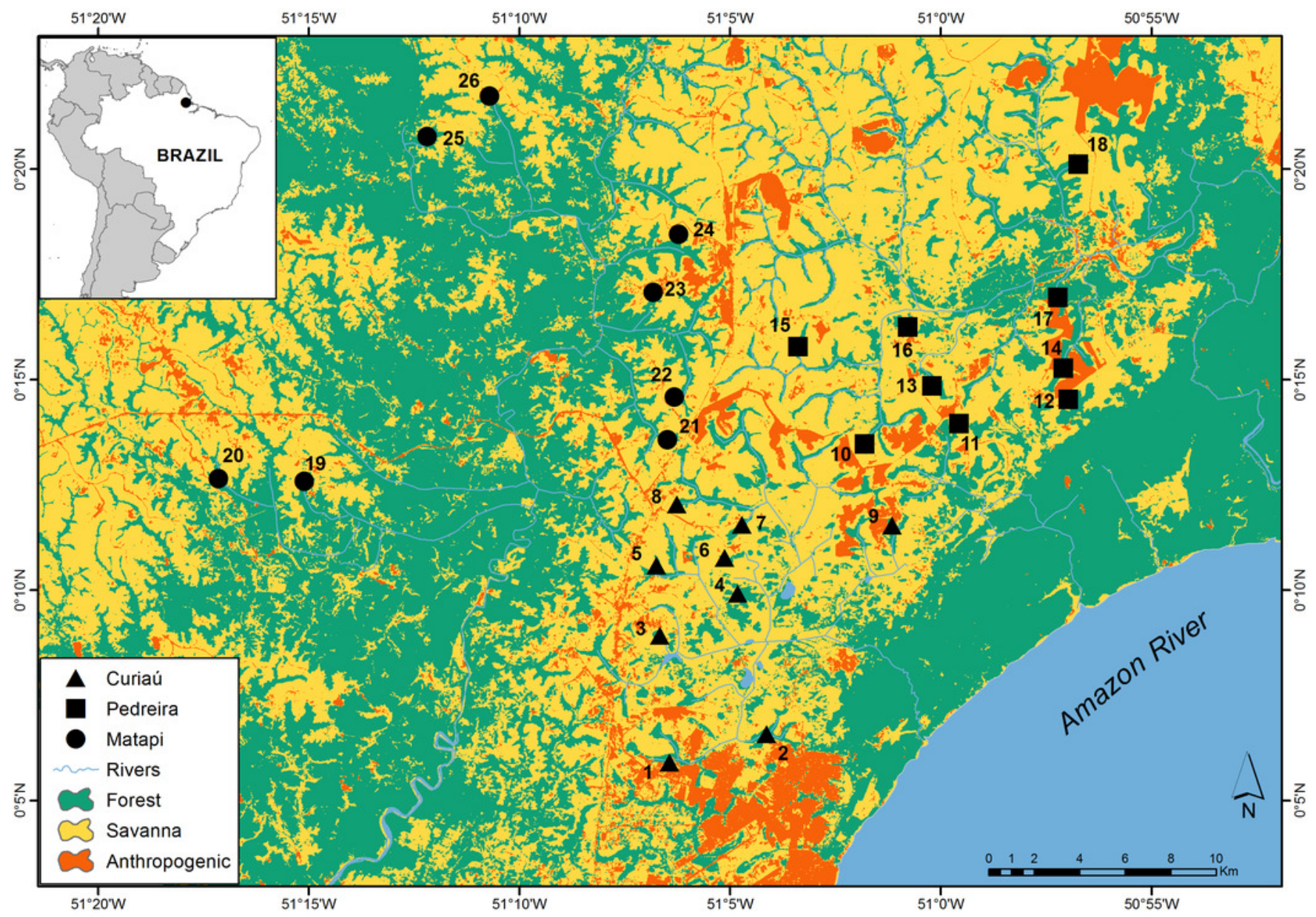




\section{Figure 2}

Univariate relationship between habitat specificity and landscape abundance $(A)$ and occupancy (B) of gallery forest birds in an Amazonian savanna landscape, Amapá, Brazil.

Each data point represents one of the 99 species evaluated. The shaded areas represent the $95 \%$ confidence intervals.
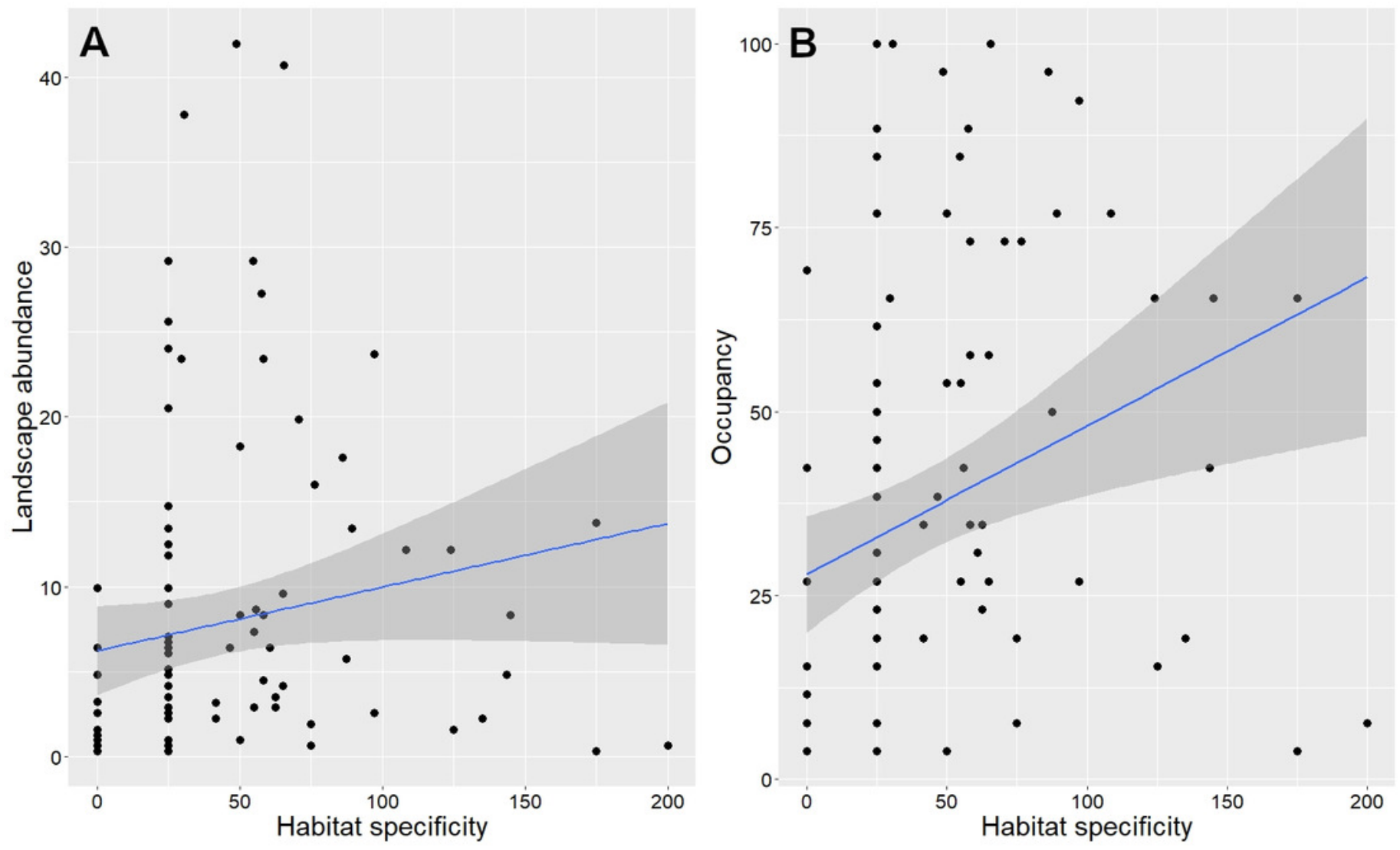


\section{Figure 3}

The percentage independent contribution of each habitat attributes (vegetation or landscape) derived by hierarchical partitioning on each dimension of biodiversity.

Codes for habitat attributes are AVH (Average height vegetation), CC (Canopy cover), UFD (Understory foliage density), FA (percentage of forest cover within $500 \mathrm{~m}$ buffer), AA (percentage of anthropogenic cover within $500 \mathrm{~m}$ buffer), SA (percentage of savanna cover within $500 \mathrm{~m}$ buffer), and FW (forest width). Significant results $(P \leq 0.05)$ are indicated with a positive or negative sign that indicates the direction of the correlation between the dimension of biodiversity and the habitat attribute.

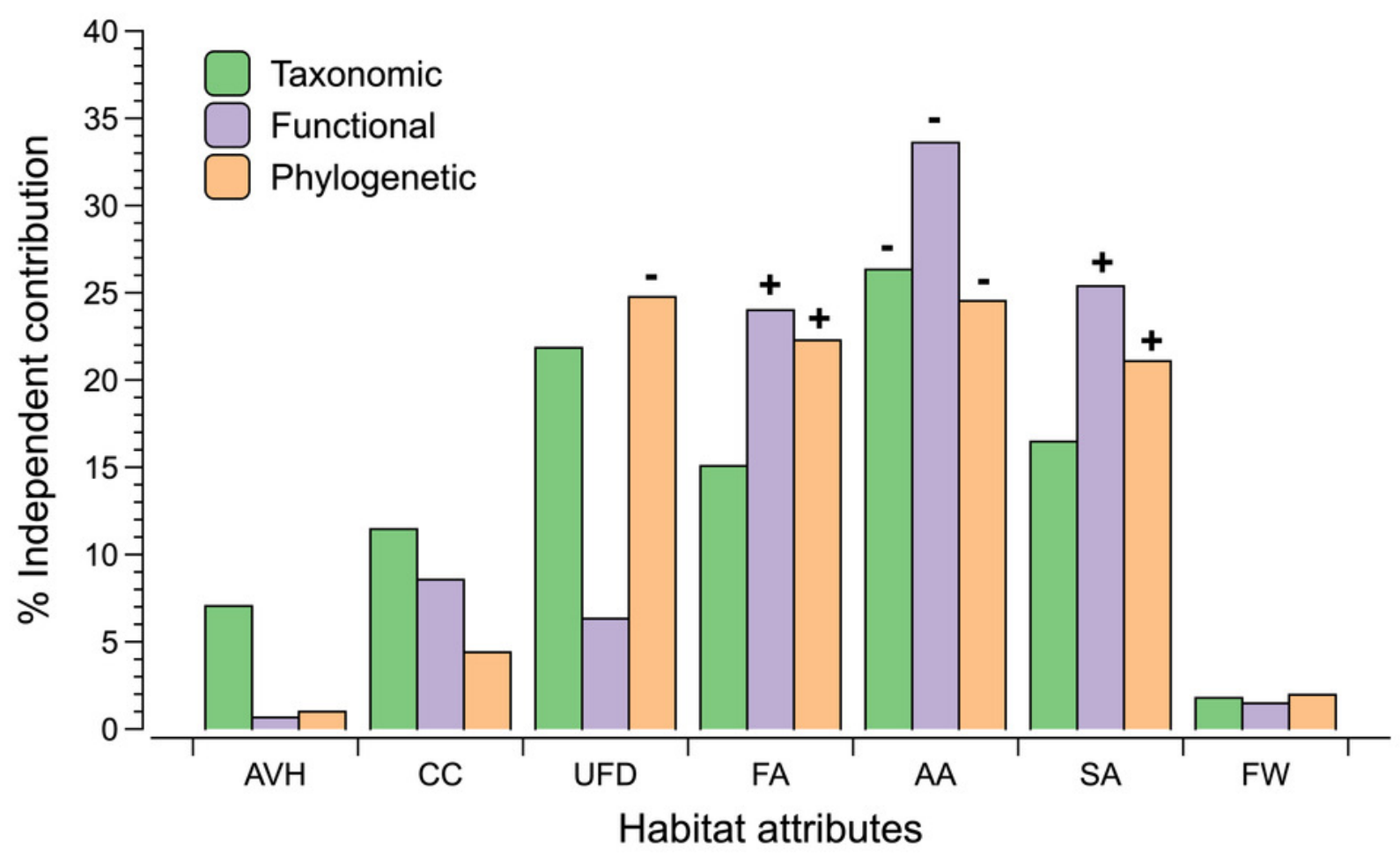


Figure 4

Taxonomic nestedness degree of the 26 local gallery forest bird assemblages in an Amazonian savanna landscape, Amapá, Brazil.

The columns represent the species, and the lines represent the sampled sites. The sites (rows) would be perfectly nested if all interactions were above the "fill line" (black curved line).

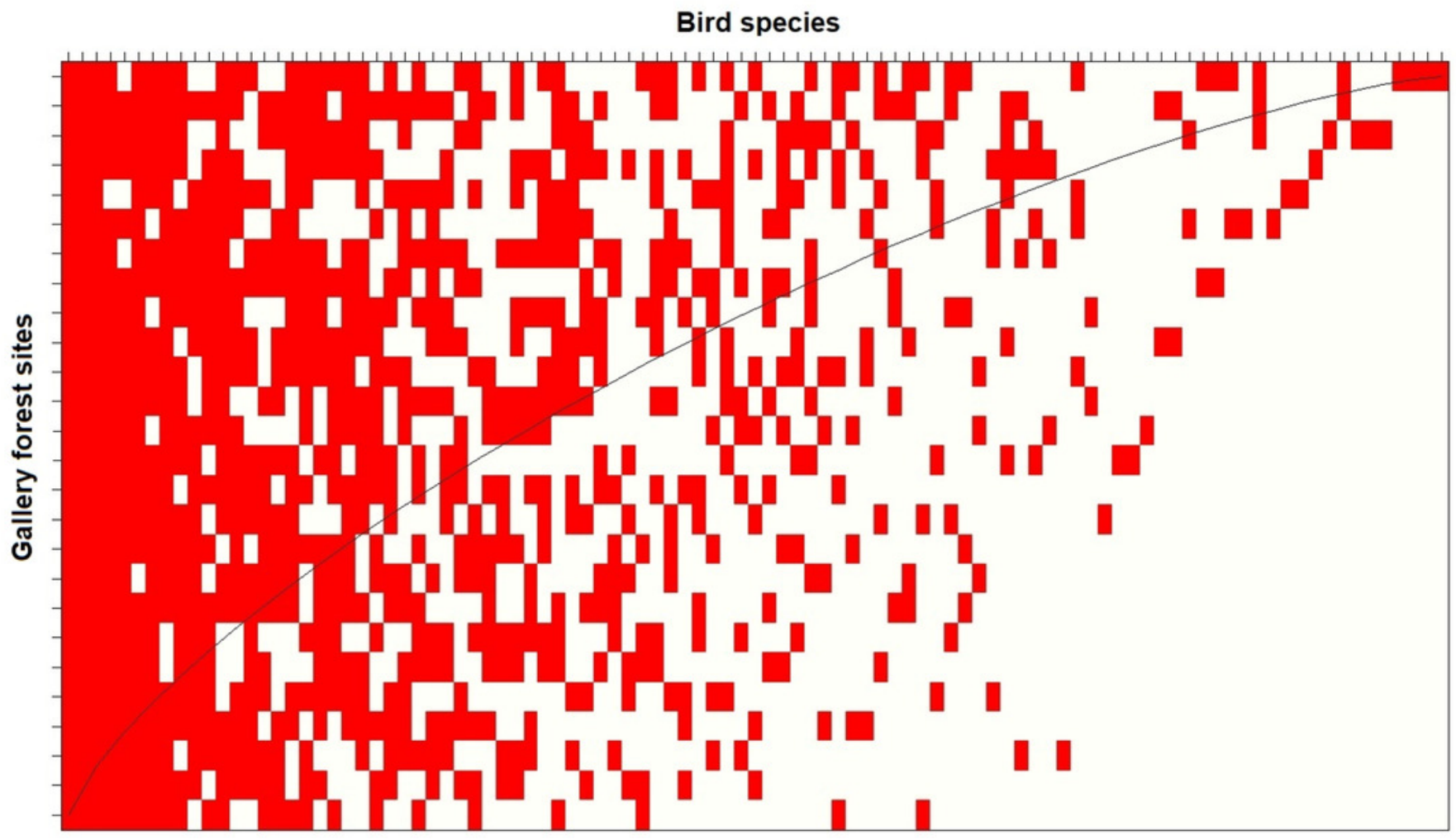

